\title{
O Solo Epistemológico de Michel Foucault: POSSIBILIDADES DE PESQUISA NO CAMPO DA ADMINISTRAÇÃO
}

\author{
The Epistemological Ground of Michel Foucault: possibilities in \\ the administration research field
}

\author{
Flávia Zimmerle da Nóbrega Costa \\ Doutoranda em Administração pela Universidade Federal de Pernambuco. Professora Assistente do Núcleo de Design da UFPE - \\ Recife-PE, Brasil. E-mail: flaviazimmerle@hotmail.com

\section{José Roberto Ferreira Guerra} \\ Doutorando em Administração na Universidade Federal de Pernambuco. Professor Substituto do departamento de Ciências \\ Administrativas da UFPE - Recife - PE, Brasil.E-mail: j.robertoguerra@gmail.com \\ André Luiz Maranhão de Souza Leão \\ Professor do Programa de Pós-Graduação em Administração da Universidade Federal de Pernambuco - Recife - PE, Brasil. E-mail: \\ aleao21@hotmail.com
}

\section{Resumo}

Tendo em vista a crise paradigmática contemporânea, colaborou-se para a corrente de defensores da possibilidade crítica na construção teórico-empírica para o campo da Administração, debruçando-se sobre o pensamento de um dos principais filósofos do conhecimento na contemporaneidade: Michel Foucault. Dessa forma, este artigo tem por objetivo abordar o conceito de solo epistemológico de Michel Foucault como uma possibilidade para que uma nova ótica crítica seja aplicada à compreensão dos fenômenos no campo da Administração. A definição de solo epistemológico é delimitada pela existência dos fundamentos culturais e pelas teorias científicas e interpretações filosóficas. Esse solo é o responsável por gerar uma ordem que emana da realidade, revelando a experiência concreta e percepção dos sujeitos. Diante da compreensão do complexo legado de Foucault, inicia-se contextualizando a trajetória teórica do filósofo nos dois ciclos interligados de sua trajetória intelectual (arqueologia e genealogia), apoiados na noção de episteme, de dispositivo e de prática.

Palavras-chave: Solo Epistemológico. Arqueologia. Genealogia. Michel Foucault. Pesquisa em Administração.

\section{Abstract}

Having the contemporary paradigmatic crisis, we contribute to the current that advocates with the critical possibility to theoretical and empirical critical to the field of Administration, looking at the thought of one of the leading philosophers of knowledge in contemporary society: Michel Foucault. Thus, this article aims to address the concept of epistemological ground of Michel Foucault as a possibility for a new critical perspective is applied to the understanding of phenomena in the field of Administration. Given the understanding of the complex legacy of Foucault, we start contextualizing the theoretical trajectory of the philosopher in his two interconnected intellectual cycles history (archeology and genealogy), supported by the notion of episteme, device and practice. We approach, in this way, some key concepts of his theoretical work, establishing relationships. We conclude the article presenting possibilities for application of the method to the field of Administration, believing that their understanding may promote the production of critical knowledge to the area.

Key words: Epistemological Ground. Archeology. Genealogy. Michel Foucault. Administration Research. 


\section{INTRODUÇÃo}

O solo epistemológico foucaultiano é caracterizado como um campo de possibilidades do saber, ou seja, uma configuração geral do saber comum, que é temporal e espacialmente determinado e formado pelo cruzamento de diferentes domínios. Sua organização, a partir da fração histórica comum aos conhecimentos, compõe visões de mundo: "[...] determina o que pode ser pensado, como pode ser pensado, dentro de que critérios, segundo qual ordem" (GUAZZELLI, 1994, p. 1). Não constitui, entretanto, apenas racionalidades e positividades específicas, mas envolve todo o jogo de coerções e limitações que se impõem em dado momento a determinado discurso vigente.

Nesse sentido, o autor afirma que se assiste, nos últimos tempos, a uma espécie de fragmentação geral de todos os solos, dos mais sólidos aos mais familiares, que provocaram um efeito inibidor às teorias totalitárias juntamente à eficácia das críticas descontínuas, particulares e locais e seu interesse pela insurreição dos saberes dominados (FOUCAULT, 1979). Devido a tais abalos, o paradigma dominante vem sofrendo uma crise epistemológica profunda e irreversível, na qual a produção de conhecimento crítico move-se entre a interpretação da crise (ontologia) e a crise da interpretação (epistemologia), de acordo com Santos (2000).

A crise paradigmática contemporânea não pode mais ser desconsiderada, já que a preocupação de grande parte dos estudos sobre epistemologia se volta para responder a três questões principais aqui envolvidas: Que é conhecimento? O que se podemos conhecer? Como conhecemos o que conhecemos? (GRECO, 2008). Como mudanças nessa ordem afetam diretamente a experiência de subjetividade humana e a construção dos saberes (CASTRO, 2009), parece adequado trazer à pauta discussões sobre construção de conhecimentos crítico e novas epistemologias para a particularidade de áreas específicas de conhecimentos.

No campo da Administração, discute-se muito sobre o rumo que as pesquisas deveriam tomar diante das transformações contemporâneas. Por um lado, questiona-se sobre os objetivos da contribuição, ou seja, se ela deveria voltar-se para aplicação e instrumentalização da gestão ou para o desenvolvimento de uma base crítica que avalie as realidades e processos organizacionais; por outro lado, discute-se a questão de escolhas diante da variedade metodológica disponível e de posicionamentos epistemológicos, num campo em que a tradição funcionalista representa a maioria das pesquisas e é responsável pelo enriquecimento $e$ aprofundamento de nossos conhecimentos sobre as organizações (SILVEIRA, 2005). Vale salientar que, para algumas perspectivas epistemológicas, tanto o método quanto a teoria assumem certa rigidez prescritiva e formal que, de modo algum, se alinham à flexibilização do conjunto aberto de práticas proposto por Foucault. (VEIGA-NETO, 2009)

Desse modo, A escolha dessa temática deve-se em primeiro lugar ao fato de o filósofo, além de ter revelado um legado epistemológico, ter proposto também uma prática investigativa (CASTRO, 2009; THIRY-CHERQUES, 2008); em segundo lugar pelo fato de essa perspectiva crítica de análise, tal como acontece em outras disciplinas (VEIGA-NETO, 2010) ser utilizada ainda de forma limitada pela maioria das investigações nos estudos organizacionais, conforme alertado por Souza, Machado e Bianco (2008). Alguns dos estudos pautados na teoria foucaultiana são caracterizados pelo uso pontual de conceitos e pela necessidade de utilização de uma colcha de retalhos conceitual de diferentes abordagens junto aos conceitos do filósofo para produção de argumentos na área. (SILVEIRA, 2005)

Veiga-Neto (2009) chama a atenção para o uso das palavras método e teoria ao trabalhar com as ideias de Foucault. Como o filósofo desloca-se em seus conceitos ao logo de sua produção, se sua pratica investigativa for entendida de forma estrita, isso implica na não existência de métodos ou teorias. Porém, se o uso desses conceitos localiza-se no seu sentido mais amplo, há métodos e teorias, sendo ambas as conclusões verdadeiras. Isso se deve ao afastamento do filósofo dos pilares da ciência moderna e do entendimento de método como um caminho seguro. Na construção de seu pensamento crítico

[...] não há um solo-base externo por onde ca-
minhar, senão que, mais do que o caminho, é o
próprio solo sobre o qual repousa esse caminho
é que é construído durante o ato de caminhar.
(VEIGA-NETO, 2009, p. 89)

Assim, entenda-se método aqui como uma "perspectiva de trabalho". Veiga-Neto (2009) salienta 
que, Foucault quase sempre evita o uso da palavra método e a descrição de seu uso se aproxima de uma "vigilância epistemológica"; já no que concerne à teoria, esta é sempre um ponto de chegada e, por ser um conjunto inacabado de práticas que se valem de diferentes métodos, a palavra mais conveniente para teoria seria teorização.

Contudo, o uso pontual revela-se problemático tendo em vista que o pensamento do filósofo constitui um raciocínio contínuo que se desloca por três domínios de investigação (constituição do sujeito do conhecimento, possibilidade de atuação sobre os outros e constituição de sujeitos éticos) e um todo metodológico que é complementar e compõe-se de um conjunto crítico que busca a vontade de verdade (arqueologia) e da busca de como esses discursos tornaram-se positividades (genealogia) (FOUCAULT, 1971). O sentido desse entendimento reflete ao mesmo tempo uma atividade de diagnóstico e um ethos da constituição da subjetivação, que é, então, um processo continuo que se estabelece na configuração sócio-histórica de pertencimento do sujeito, e que se constitui como praticas de si. Essas práticas representam, ao mesmo tempo, um modo de objetivação desse sujeito.

Colaborando para a corrente de defensores da possibilidade crítica na construção teórico-empírica para o campo, exatamente no quesito de defesa de uma concepção teórica alinhada à prática (BATISTA-DOS-SANTOS et al., 2010), o presente ensaio propõe revisar as noções centrais que compõem a noção de solo epistemológico de Michel Foucault tendo em vista uma discussão sobre o potencial de sua utilização para a área de Administração.

\section{A Trajetória Teórica de Foucault: da EPISTEME AO DISPOSITIVO E À PRÁTICA}

Tendo em vista a compreensão do complexo legado de Michel Foucault, iniciou-se por contextualizar sua trajetória teórica. O autor se destacou como um dos filósofos que refletiram mais profundamente acerca do saber como construção história, propondo um novo olhar para compreensão de temas e teorias. Em seu percurso teórico, discorreu sobre questões como a loucura, a governança, a moral e a disciplina, trazendo à luz um legado epistemológico e também uma prática investigativa que anula qualquer pretensão dos saberes como verdades objetivas. (CASTRO, 2009; THIRY-CHERQUES, 2008)

Os dois ciclos totalmente interligados de sua vertente epistemológica constituem a possibilidade de conhecer (denominada arqueologia) e a tática que liberta os saberes da sujeição presentes na discursividade (denominada genealogia). O primeiro ciclo parte de uma questão kantiana: a determinação da possibilidade de conhecer; o segundo se baseia em Nietzsche: a impossibilidade de libertação da nossa própria condição histórica. Nietzsche constatou que, em cada circunstância, as palavras, os desejos e as ideias variam em suas lógicas e sentidos (THIRY-CHERQUES, 2008). Essa constatação inspirou Foucault a fixar sua análise nos cenários e nos pontos de ruptura e diagnosticar as relações entre o poder e o saber, entendendo o poder como uma relação que não se localiza em um ponto específico, mas está presente em toda a rede discursiva. Assim, a partir da década de 1970, em seu segundo ciclo, Foucault desloca-se do eixo do saber para o eixo do poder e da ética. Essas três fases: saber, poder e ética correspondem às noções de episteme, dispositivo $e$ prática. (CASTRO, 2009)

No primeiro ciclo, especialmente em As Palavras e as Coisas e Arqueologia do Saber, Foucault situa sua análise na descrição da episteme e nas dificuldades metodológicas que esta origina. Em obras seguintes, Vigiar e Punir e A vontade do Saber, o autor desloca-se do conceito de episteme para o de dispositivo, ou seja, deixa o objeto de descrição arqueológica e volta-se à exploração do objeto do ciclo genealógico, em parte como respostas às dificuldades anteriores de não poder descrever a mudança em si mesma, apenas seus resultados, e, por outro lado, visando explorar as relações entre o discursivo e o não discursivo, introduz a análise das questões de poder envolvidas na produção dos saberes. Nesse deslocamento, o autor deixa claro que a formação do saber não é uma consequência apenas da episteme, mas fruto também de práticas disciplinares historicamente analisáveis. A passagem para a terceira fase do segundo ciclo - a prática - dá-se pela identificação da insuficiência dos instrumentos teóricos para realizar as análises do poder, levando o autor a desenvolver novos conceitos. Tais conceitos (como governo $e$ governamentalidade) entrecruzam-se com noção de 
ética e construção do sujeito, envolvendo temas como o cuidado de si, a moral, as formas de subjetivação e objetivação, entre outros. (CASTRO, 2009; SILVEIRA, 2005; THIRY-CHERQUES, 2008)

Assim, apesar de as teorias de Foucault apresentarem deslocamentos de conceitos e objetos, não implica quebra alguma em seu pensamento conceitual. Não existem dois métodos: "a genealogia apoia-se sobre a arqueologia e a completa” (THIRY-CHERQUES, 2008, p. 229). Ao se interessar pelos demais domínios na fase genealógica, Foucault não torna irrelevante a arqueologia e, apesar de não mais se referir à sua especificidade, articula um "todo metodológico", uma techné ("Falar em 'uma atividade', uma 'maneira de entender', um 'modo de ver as coisas' remete à noção de techné". (VEIGA-NETO, 2009, p. 89)) de investigação, uma "incorporação" metodológica sucessiva que vai do primeiro ao terceiro domínio. (VEIGA-NETO, 2009)

Conforme salienta-se, método e teoria para Foucault possuem um entendimento específico. Assim também o termo techné não se refere a determinada técnica investigativa, mas trata-se de uma aplicação proveniente do seu sentido grego: Platão considera techné ou ofício como análogos à prática da virtude. Segundo (LUNA, 2009) a virtude é uma "techné tou biou" que pode ser traduzido literalmente como "arte da vida" ou poeticamente como a "estética da existência", tal como explorada por Foucault. Com a techné o sujeito estiliza ou cria para si os moldes de um homem virtuoso, o que implica envolver questões de moral e ética diretamente ligada à ação de pessoas. A estética é única: uma construção individual de um sujeito de ação. Mas, apesar da construção ter o compromisso com a individualidade, como a subjetividade é constituída na cultura, está impregnada de ethos social e diz respeito às práticas morais. Contudo, Foucault não busca apenas o entendimento de como a ética constitui a subjetividade, mas também o porquê dessa ação individual.

Assim, a techné de investigação refere-se a um modo de ação, um modo de ação analítico e de entendimento que utiliza do mesmo ferramental nos dois ciclos, o que torna a diferença entre eles vaga e difusa. Porém, enquanto a arqueologia trata do nível de onde as coisas são organizadas para produzir formas gerenciáveis de conhecimento, a genealogia busca as razões do estabelecimento do verdadeiro e do falso por meio dos mecanismos de poder. (O'FARREL, 2010)

A seguir tratar-se-á de cada ciclo.

\section{A Arqueologia como Primeiro Ciclo: A CONSTRUÇÃo do SABER}

O primeiro ciclo do autor trata da análise arqueológica e propôs o estudo dos saberes desvinculado dos limites da história e de demais disciplinas. Seu objetivo foi estabelecer a relação entre os saberes levantando sua positividade específica, ou seja, fez vir à tona o que foi efetivamente dito em determinado momento histórico sobre determinado tema. Nos livros a História da Loucura (1961), o Nascimento da Clínica (1963) e As Palauras e as Coisas (1966), o autor demonstra a utilização dos instrumentos metodológicos da arqueologia, que posteriormente são sistematizados no livro Arqueologia do Saber (1969). O projeto arqueológico objetiva responder como os saberes surgem e se transformam, o que possibilita a abertura de um novo rumo para as análises históricas, desvelando as condições dessa aparição e as questões institucionais e políticas. Desse modo, estabelece as descontinuidades $e$ as regras de transformação, além da articulação dos saberes com a estrutura social, institucionais e políticas. (THIRY-CHERQUES, 2008)

A arqueologia investiga as condições históricas de possibilidades do saber partindo de sua condição interna de ordem e modos de ser, evitando a interpretação dos documentos, que são descritos como práticas, $e$ não como signos de outras coisas. O conceito arqueológico é tributário de uma teoria da linguagem, que deixou sua vigência de representação, sendo a condição de verdade revelada de forma pragmática, pela rede discursiva formada no conjunto dos fenômenos investigados. (FOUCAULT, 2007; THIRY-CHERQUES, 2008)

A episteme refere-se à ordem interna que constitui a positividade de todo saber, uma forma que configura e determina uma época (THIRY-CHERQUES, 2008). Considera apenas o discursivo, ou seja, as práticas discursivas:

[...] um conjunto de regras anônimas, históricas, sempre determinadas no tempo e no espaço, 
que definiram, para uma época dada e para uma área social, econômica, geográfica ou linguística dada, as condições de exercício da função enunciativa. (FOUCAULT, 2007, p. 154)

$\mathrm{O}$ método arqueológico diferencia-se de outros convencionalmente aceitos por não permitir ser esquematizado: redefine permanentemente seus objetivos, seu sistema de argumentação e seus princípios (THIRY-CHERQUES, 2008). Castro (2009) estabelece quatro diferenças essenciais para o método: 1) a arqueologia não está interessada em descobrir o momento de surgimento de algo, mas na regularidade dos enunciados; 2) as formações discursivas não representam um texto contínuo, consideram as incoerências internas encontradas na rede discursiva; 3) não pretende ser uma análise causal, e sim mostra de como a história pode dar lugar a tipos definidos de discursos; e 4) as várias transformações de uma época permitem numerosas relações possíveis, constituindo-se em práticas discursivas determinadas.

Como para Foucault o sujeito é constituído simbolicamente por práticas historicamente analisáveis (modos de objetivação/subjetivação) (CASTRO, 2009; FAIRCLOUGH, 2001; FOUCAULT, 2007; THIRY-CHERQUES, 2008), na arqueologia as estruturas do conhecimento e os modos de compreensão estão articulados no tempo, no espaço e na instituição e são regidas por regras provenientes da relação específica entre os elementos discursivos e não discursivos, formando uma rede de práticas discursivas exclusivas (FAIRCLOUGH, 2001; FOUCAULT, 2007). A ordem interna constitutiva do saber revela uma episteme, uma condição de possibilidade histórica singular, em que se definem e estruturam os múltiplos saberes do período e que, por isso, compartilham formas gerais. $\mathrm{O}$ discurso, para o trabalho arqueológico, é um conjunto de enunciados que constitui o social, seus objetos $e$ sujeitos em práticas discursivas inter-relacionadas, que provêm de um mesmo sistema de formação (FOUCAULT, 2007). A arqueologia é a análise de discurso do arquivo, cuja investigação volta-se para a estrutura ou articulação das formações discursivas que geram a ordem do discurso, e a busca é por localizar os efeitos da prática discursiva sobre a construção dos saberes (CASTRO, 2009; FAIRCLOUGH, 2001; FOUCAULT, 2007; THIRY-CHERQUES, 2008). O Quadro 1 sintetiza os principais conceitos elaborados por Foucault agrupados em torno da análise arqueológica.

\begin{tabular}{|c|c|}
\hline Episteme & $\begin{array}{l}\text { É o paradigma que estrutura os múltiplos saberes } \\
\text { em determinado período, relacionando os } \\
\text { diferentes tipos de discursos: filosóficos, técnicos, } \\
\text { institucionais, sociais, econômicos, políticos, etc. }\end{array}$ \\
\hline Dispositivo & $\begin{array}{l}\text { Noção mais ampla que a episteme adotada } \\
\text { posteriormente por Foucault: inclui a episteme } \\
\text { e todo o social não discursivo, ou seja, além dos } \\
\text { discursos, práticas, instituições e táticas. }\end{array}$ \\
\hline Discursivo & $\begin{array}{l}\text { Refere-se a documentos literários e não literários } \\
\text { que referenciam determinada época. }\end{array}$ \\
\hline Não discursivo & $\begin{array}{l}\text { Refere-se às práticas como os modos de ser, de } \\
\text { comportar-se. }\end{array}$ \\
\hline Arquivo & Contém todo o dispositivo. \\
\hline $\begin{array}{l}\text { Saber/ } \\
\text { Conhecimento }\end{array}$ & $\begin{array}{l}\text { O saber inclui, além dos conhecimentos formais } \\
\text { e sua trajetória própria racional, as instituições } \\
\text { e práticas de atividades do conhecimento não } \\
\text { formal: as percepções e saberes não científicos. }\end{array}$ \\
\hline Decifração & $\begin{array}{l}\text { É a forma de compreensão de descontinuidades } \\
\text { históricas: devem ser reveladas, descobertas, e } \\
\text { não estabelecidas. }\end{array}$ \\
\hline Enunciado & $\begin{array}{l}\text { É um conjunto de signos considerados no nível } \\
\text { de sua existência, ou seja, o enunciado é o que } \\
\text { dá o saber. }\end{array}$ \\
\hline $\begin{array}{l}\text { Descrições } \\
\text { enunciativas }\end{array}$ & $\begin{array}{l}\text { Representam a unidade enunciativa de uma } \\
\text { pesquisa. }\end{array}$ \\
\hline Funções & $\begin{array}{l}\text { São ações que se revelam na prática enunciativa } \\
\text { pela existência de um domínio de saberes a elas } \\
\text { associada. }\end{array}$ \\
\hline Regras & $\begin{array}{l}\text { São práticas sociais que geram sentido aos signos, } \\
\text { na condição de existência e permanência de } \\
\text { elementos em cada repartição (séries) discursiva. }\end{array}$ \\
\hline
\end{tabular}

Quadro 1: Principais Conceitos da Análise Arqueológica Fonte: Adaptado de Foucault (2007), Thiry-Cherques (2008) e Castro (2009)

Para a prática arqueológica, é fundamental desenvolver a compreensão de duas arenas da informação: o saber e o conhecimento. (THIRY-CHERQUES, 2008; SCHEURICH; MCKENZIE, 2005)

\section{A Genealogia como Segundo Ciclo: O PODER COMO INSTRUMENTO DE ANÁLISE E CONSTRUÇÃO DO SUJEITO}

O segundo ciclo foucaultiano se propõe a responder o porquê do aparecimento dos saberes, partindo de condições externas de possibilidades desses saberes. Nessa etapa, encontram-se os livros Vigiar e Punir (1974) e A Vontade do Saber (1976), que é o primei- 
ro tomo da História da Sexualidade (MACHADO, 1979; THIRY-CHERQUES, 2008). Na genealogia ocorre um deslocamento de ênfase: a questão da análise discursiva perde a centralidade na investigação, sendo o procedimento determinado pela relação entre os grupos discursivos e as condições de seu aparecimento e transformação. Tais condições abrangem o econômico, o político, o histórico e o cultural (THIRY-CHERQUES, 2008). Esse processo constitui-se uma insurreição dos saberes contra os efeitos centralizadores de poder do discurso considerado científico, liberando da sujeição os saberes históricos. (FOUCAULT, 1971)

A genealogia considera que o saber e o poder se apoiam e reforçam mutuamente, pois o saber é um elemento do dispositivo político (CASTRO, 2009). Como os saberes são objetos de relações de poder em um discurso político, as formas de exercício de poder são um instrumento de análise que pode explicar a produção dos saberes. Esse modo de entendimento provocou um deslocamento respeitável nas análises da ciência política que, até então, tinham o Estado como o centro desse tipo de relação. O poder deixa de ser visto como uma ação centralizada e global do Estado e seu aparelhamento, para ser encontrado no nível elementar com sua existência própria, independente e autônoma (MACHADO, 1979). Desse modo, a mudança de ponto de vista foi tanto do espaço onde se efetuam as análises (do saber para o poder), quanto no nível em que acontece (do macro para o micro). Quando é desautorizada a ideia do Estado como órgão central e único do poder, bem como da rede de poderes das sociedades como uma extensão dos efeitos do Estado, esses dois tipos de poderes se apresentam com uma autonomia relativa, podendo ter ou não uma ligação.

O poder para Foucault foi uma estratégia de pensamento que embasou a possibilidade de seu método analítico: o seu objetivo foi a análise das diferentes formas pelas quais os indivíduos tornaram-se sujeitos na história. Nesse sentido, ao buscar analisar como estes foram objetivados, desenvolveu a analítica do poder. Essa analítica não representa uma teoria nem do sujeito nem do poder, mas, sim, um mapeamento da complexa rede de relações de poder e resistência existente no interior do campo discursivo em que os sujeitos foram objetivados (MACHADO, 2010). Desse modo, o poder não se constitui uma onipresença, pois se produz continuamente e localiza-se em diversos pon- tos da rede discursiva. O nível molecular de exercício de poder foi uma das principais preocupações metodológicas da análise ascendente que Foucault propôs.

Assim, o filósofo desconsidera uma concepção de poder inspirada no movimento econômico ou jurídico (poder que não passa nem ao nível do direito nem da violência, pois não se estabelecem por relações contratuais ou repressivas) (MACHADO, 1979). O poder é concebido como luta (inspiração em Nietzsche), mas não deve ser buscado nem na batalha nem no acordo, mas no modo de ação que é o governo, ou seja, o funcionamento do poder deve ser buscado no conceito de governo, no qual a liberdade é a sua condição de existência. O poder é uma relação que opera num campo de possibilidades, algo que se exerce, e não algo que se possui. Relações de poder são jogos, não têm enfrentamentos, e sim resistências (FOUCAULT, 1979). Desse modo, considerando o poder como jogos estratégicos entre liberdades, o autor demarca a diferença entre poder e dominação (estados de dominação) (LEMKE, 2000). O poder como estratégia é uma característica das relações humanas que não necessariamente se exerce contra a vontade do outro ou se realiza como uma coisa ruim. Já a dominação é uma relação hierárquica impositiva, na qual a liberdade dos subordinados é limitada.

No momento em que incorpora as relações do não discursivo (relações de poder) ao discursivo, Foucault amplia a noção de episteme para dispositivo. Contudo, para o autor, tanto a episteme quanto o dispositivo são práticas. O conceito de prática representa para Foucault a regularidade e a racionalidade que organizam as ações humanas, "[...] que tem um caráter sistemático (saber, poder, ética), e geral (recorrente) e, por isso, constituem uma experiência ou um pensamento" (CASTRO, 2009, p. 338). O poder disciplinar representa a criação do indivíduo, este é um de seus efeitos mais importantes: a individualidade investida de poder que é habitualmente citada como anterior ao capitalismo na verdade representou "uma massa confusa, desordenada e desordeira" (MACHADO, 1979, p. XIX), e a investigação disciplinar fez surgir o indivíduo como alvo do poder em meio à multiplicidade ordenada de dados.

No último capítulo do livro A Vontade de Saber, Foucault demonstra que os dispositivos não são apenas do tipo disciplinar, mas que também se realizam 
buscando regular populações, levando o biopoder (Biopoder é o poder sobre a vida (biopolítica) nasce no momento em que o homem adquire existência política $e$ a vida biologicamente considerada converte-se no objeto de governo. As sociedades modernas não são apenas sociedades de disciplinarização, mas de normalização do indivíduo e das populações), as regulações e os dispositivos de segurança para ordem das ciências sociais: a série de fatos e causas que concorreram para a formação do Estado trouxe para as análises a noção de governo e governamentalidade, que "[...] tem na população seu objeto, na economia seu saber mais importante e nos dispositivos de segurança seus mecanismos básicos". (MACHADO, 1979, p. XXIII)

Os temas de governo e governamentalidade surgem pela insuficiência de instrumentos teóricos para análise do poder. Esses dois conceitos são centrais para compreender o tema de estudo de Foucault: o sujeito (e não o saber ou o poder) e sua analítica de poder. Contudo, a problemática de governo ainda pouco conhecida, pois a totalidade do material não foi ainda publicada pelo Collège de France (CASTRO, 2009; LEMKE, 2000). O conceito de governamentalidade refere-se à ligação semântica entre as palavras governar (gouverner) e modos de pensamento (mentalidades) (LEMKE, 2000). Para Foucault, esse conceito se refere às formas da arte de governar e estuda formas de racionalidade, procedimentos técnicos, formas de instrumentalização. A arte de governar inclui o estudo do governo de si (ética), o governo dos outros (formas políticas de governamentalidade) e as relações entre o governo de si e o dos outros. Desse modo, governamentalidade traz uma visão sobre o poder como uma relação entre tecnologias do eu e da dominação, a construção do sujeito e a formação do Estado, demarcando claramente a diferença entre poder e dominação, avançando teoricamente em relação à proposta de Nietzsche. (CASTRO, 2009; LEMKE, 2000).

O conceito de governo possui dois eixos: o governo como relação entre sujeitos e o governo como relação consigo mesmo, ou seja, governar é conduzir condutas, ou ainda a conduta da conduta. No momento em que a ideia de governo é usada para investigar as relações entre as tecnologias do eu e da dominação, dá-se uma ruptura teórica na problematização do poder, o que não implica uma quebra do pensamento conceitual do autor (LEMKE, 2000). A noção de governo tem aqui um sentido abrangente, voltado para uma antiga concepção do termo (O governo já foi um termo discutido em vários setores além do político: filosofia, religião, medicina, etc. Segundo Foucault (1979), o texto La mothe La Vayer define três tipos de governo: o de si mesmo (moral), da arte de governar uma família (economia) e a ciência de bem governar (Estado). Essas artes de governar possuem uma continuidade essencial entre elas, de forma ascendente (para governar o Estado tem que saber governar a si e a seu patrimônio) e descendente (o governo do Estado repercute na gestão da família e na conduta das pessoas). A partir do século XVIII, a família deixa de ser modelo de governo para ser instrumento de governo: desbloqueando a arte de governar, táticas e técnicas novas têm por fim e instrumento a população, e a economia política ganha um sentido novo. Desde essa época, vive-se a governamentalização do Estado (espaço real da luta política), cujos limites requer que se compreenda a partir das táticas de governamentalidade): ocupa-se do governo de si mesmo e dos outros, possuindo uma estreita ligação entre as formas de poder os modos de objetivação e de subjetivação, que se encontram entre esses dois eixos. Os modos de subjetivação são as práticas de constituição do sujeito presentes em sua história em sua cultura, $e$ as formas de objetivação são os modos em que o sujeito foi objeto de saber e de poder para si e para os outros. Essas duas formas (objetivação e subjetivação) possuem um desenvolvimento mútuo.

Por meio da formação e transformação na cultura das relações consigo mesmo, com seu arcabouço técnico e seus efeitos de saber, a história do cuidado de si é uma maneira de constituir a história da subjetividade. O conceito de cuidado de si envolve o governo de si mesmo por si mesmo e sua articulação com as relações com os outros, do mesmo modo que o governo (de si e dos outros). Todo esse domínio da constituição de si mesmo como sujeito moral refere-se ao conceito de ética, ou seja, revela um modo de ser e de se conduzir. A ação moral é indissociável das formas de atividade sobre si mesmo. Toda moral comporta um código de comportamento, uma relação com o real (realização e código) e consigo mesmo. Por essa razão, qualquer intenção de libertação precisa embasar-se em novas formas de subjetividade, diferenciada da que nos é dada historicamente. O Quadro 2 sintetiza os principais 
termos-chave da análise genealógica elaborados por Foucault.

$\begin{array}{ll}\text { Sujeito } & \begin{array}{l}\text { Sua constituição é o tema central das } \\ \text { investigações de Foucault. }\end{array} \\ \text { Saber/Poder } & \begin{array}{l}\text { Apoiam-se e reforçam-se mutuamente, } \\ \text { sendo o poder concebido como uma luta, } \\ \text { uma prática. }\end{array} \\ & \begin{array}{l}\text { Ocupa-se das questões do governo de } \\ \text { si mesmo e dos outros. Tem um sentido } \\ \text { abrangente voltado para a velha acepção } \\ \text { do termo governo e esboça uma estreita } \\ \text { ligação entre as formas de poder e processos }\end{array} \\ \text { de subjetivação. } \\ \text { Bovernamentalidade }\end{array}$

Quadro 2: Principais Conceitos da Análise Genealógica Fonte: Adaptado de Foucault (2007), Thiry-Cherques (2008) e Castro (2009).

Para a regulação da vida nas sociedades de normalização, o autor identifica duas modalidades de poder: a disciplina e o biopolítica, ambas eixos do biopoder. A disciplina se apresenta como uma forma discursiva de controle da produção de novos discursos (na ordem do saber) ou ainda representa uma forma de exercício de poder que tem por objeto os corpos e por objetivo sua normalização (na ordem do poder).
As relações de disciplina assumiram uma anatomia política: o panóptico, uma composição arquitetônica de Bentham que assegura a vigilância por meio da distribuição de visibilidade espacial. O panoptismo foi uma invenção tecnológica da ordem do poder que se automatiza e desindividualiza. (CASTRO, 2009)

Desse modo, Foucault faz uma abordagem histórica da questão da subjetividade e, em oposição à visão cartesiana, afirma que o sujeito é uma forma que não é idêntica a si mesma. O problema do sujeito é sempre o problema da forma-sujeito. Todo seu trabalho volta-se para a análise filosófico-histórica das práticas de subjetivação, que revelam formas de objetivação, ou seja, os modos como o sujeito foi objeto de saber e de poder.

\section{O Solo Epistemológico de Foucault como UMa PossibILIDAde para a Pesquisa no Campo da AdMINISTRAÇÃo}

O campo de Administração, em suas diversas áreas, depara-se cotidianamente com uma série de fenômenos que envolvem relações de caráter inter $e$ intraorganizacionais, cujos jogos de poder e princípios compartilhados requerem mais que uma explicação: impõem aos pesquisadores a necessidade de compreensão, do pleno entendimento dessas realidades em suas particularidades e complexidades.

Enxerga-se que esse caminho teórico-metodológico para a área de Estudos Organizacionais poderia auxiliar o entendimento dos discursos institucionalizadores, desinstitucionalizadores e reinstitucionalizadores que firmaram laços entre atores, desencadearam posições discursivas legitimadas, produziram sentidos $e$ interferiram na forma de entendimento de realidades internas e externas às organizações, a esta determinantes. O uso desse recurso poderia contribuir, inclusive, para a ampliação e o refinamento de discussões sobre a compreensão da própria relação de poder, como, por exemplo, as investigações passarem a considerar a influência do poder entendido como "não disciplinar" (e sua articulação), que está presente nos diversos sistemas de informações ao longo da cadeia hierárquica organizacional, desde a descrição de tarefas, avaliação 
de desempenho, modos de controle informais, entre outras. Tal perspectiva levantaria as possibilidades de entendimento de como certas posições discursivas disciplinam e conduzem pessoas e como essas práticas colaboram ou não para o desempenho de funções específicas e, em última instância, da própria instituição. Discutir e problematizar a governança corporativa, bem como a transparência nessas práticas, auxilia a traçar novas possibilidades de gestão.

No âmbito da Administração Pública, entende-se que as ideias desse filósofo podem colaborar com o auxílio da governabilidade, uma vez que irão gerar conhecimento acerca das relações do Estado com a sociedade e com as demais empresas do Terceiro Setor. A partir de tais entendimentos é possível traçar agendas de política públicas e programas governamentais, bem como levantar dados de análise da relevância da atuação dessas polícias na percepção da sociedade, sendo um gerador de justiça e equidade e cumprindo um dos papéis fundamentais do Estado. De modo análogo, a Gestão de Processos Inovadores constitui-se de uma gama de ações empreendedoras necessárias à conquista de excelência e vantagens em relação à concorrência. A aplicação da noção de governamentalidade foucaultiana permitiria uma compreensão das dinâmicas de governo organizacionais: o impacto social e competitivo desses projetos, suas demandas de ação e processos.

No que concerne à Administração da Informação, esse pensamento pode apontar dados preciosos para um sistema integrado de gestão, tornando mais fácil diagnosticar pontos específicos com problemas dentro das cadeias colaborativas, fornecendo subsídios importantes para solução destes. Entre outras possibilidades, as soluções para os fluxos de informação podem estar na regulação adequada, portanto diferenciada, para cada um dos diversos contextos. Em geral, observa-se que a normatização define, de forma ampla, os procedimentos de correção e controle, estabelecendo o que deve (pode) ou não deve (não pode) ser feito. A adoção desta análise poderia indicar a existência $e$ a necessidade de diferentes tipos de normalidades.

Para o campo da Estratégia é essencial manter-se informado e atualizado quanto às análises de ambientes externos e internos. Esses contextos são mantidos por processos regulatórios e mecanismos normativos, travados no interior de lutas e jogos de poder que os sustentam. A partir da compreensão analítica foucaultiana, é possível traçar estratégias corporativas para as diversas áreas de conhecimento e inovação, produção de sentidos e posicionamentos mercadológicos, bem como em áreas específicas de finanças, marketing e recursos humanos. Gerar esse conhecimento sobre os ambientes orienta os processos decisórios organizacionais, bem como o planejamento de ações: a curto e a longo prazos.

A compreensão do ambiente externo e do cliente é uma preocupação da área de Marketing. Nesse sentido, a potencialidade dos conceitos foucaultianos seria uma forma alternativa de construção de conhecimento para este campo: aflorar a rede de saber e poder que cruza os diversos níveis relacionais permitiria a compreensão da percepção dos diversos atores do processo, afloraria significados e influências que perpassam por todo escopo de serviços, além de revelar práticas de consumo. A adoção da reflexão de solo epistemológico para esta rede nos colocaria diante de uma postura crítica sobre tais relações. Essas descobertas repercutem, entre outras coisas, no surgimento do homem no espaço de representação (FOUCAULT, 2007), ou seja, a visão dos produtores e consumidores como sujeitos. Por outro lado, essa análise poderia desvelar os instrumentos e mecanismos internos necessários e mais adequados para condução dos grupos, indicando os caminhos para o melhor resultado na gestão deles.

Analisar realidades corporativas permite verificar possibilidades de maior participação dos funcionários e desenvolve novas técnicas gerenciais. Devido às constantes mudanças no âmbito empresarial, as dinâmicas socioculturais das organizações demandam um esforço diário para os líderes compreenderem os sistemas simbólicos que abarcam as diversas atuações humanas. Esse entendimento pode proporcionar respostas estratégicas para os problemas organizacionais pautadas em formatos orgânicos de tomada de decisão, o que possibilita o incremento da qualidade de custose na velocidade das transações, por exemplo. $\mathrm{O}$ destaque dado ao processo de conhecer as coisas por meio deste pensamento possibilitará reconhecer a forte existência de significados e discursos apriorísticos a uma dada 
realidade. Essas construções de significados estão atreladas, então, a interesses e a limitações referentes ao recorte temporal e espacial no qual o conhecimento foi elaborado. Para Foucault, o a priori histórico representa um princípio de redução externa, uma relação de desequilíbrio entre uma prática investigativa e um tema da pesquisa. Nesse sentido, visualiza-se que a adoção do conceito de solo epistemológico seria de grande valia para as pesquisas em todos os campos da Administração.

A definição de solo epistemológico é delimitada pela existência dos fundamentos culturais e pelas teorias científicas e interpretações filosóficas. Esse solo é o responsável por gerar uma ordem que emana da realidade, revelando a experiência concreta e percepção dos sujeitos. Pode-se visualizar a aplicação desse conceito de forma geral, no que concerne às relações estabelecidas entre a organização e seus interagentes, na tentativa de identificar a construção de uma realidade comum em torno de um discurso. Assim, pode-se localizar o solo epistemológico também entre as coisas e os sujeitos, ou seja, entre as propriedades imanentes dos objetos e a linguagem humana. Nesse sentido, a ordem seria responsável pela criação/sustentação de um sistema de elementos que proveem as coisas de características que nos auxiliam a classificá-las, defini-las e agrupá-las em determinados conjuntos. Pode-se perceber que a relação entre cultura, solo epistemológico e conhecimento científico representa um continuum entre ordem, reflexão e autoconsciência, respectivamente. (FOUCAULT, 2007)

A ordem do solo epistemológico pode ser vista como uma tábua sobre a qual organizam-se os sistemas de identidades, similitudes e analogias que garantem uma coerência mínima para o exercício empírico de ordenamento da realidade. Como forma de acessar as relações entre cultura, solo epistemológico e conhecimento científico e compreender suas características internas e busca pela ordem, Foucault propõe a utilização do método da arqueologia conforme já foi visto. Esse método visa clarificar o conhecimento dos princípios e das condições da possibilidade dos saberes em um dado contexto sócio-histórico. Um dos pontos de destaque seria o cruzamento entre a linguagem e o espaço, ou seja, um diálogo entre a possibilidade do conhecimento e a nomeação da realidade, por fim, um diálogo entre o material e o imaterial.

\section{Considerações Finais}

Propõe-se gerar novas reflexões críticas a partir da adoção do legado epistemológico foucaultiano. Nesse sentido, em nosso percurso pela trajetória dos pensamentos de Michel Foucault, aborda-se o entendimento do saber como uma possibilidade arqueológica e do poder como uma relação disseminada que se instaura no próprio discurso. A arqueologia é um método que permite a compreensão discursiva em sua multiplicidade se adequando a várias questões investigativas do campo. Considerar a questão do poder amparado na construção da genealogia foucaultiana abre também inúmeras possibilidades de investigação para as análises organizacionais, seja sob o aspecto externo à organização, como os processos de comunicação, por exemplo, seja internamente, nas múltiplas práticas cotidianas que mantêm o sistema em funcionamento.

Assim, a adoção do projeto epistemológico foucaultiano atrelada a uma construção paradigmática de estratégias e métodos de pesquisa alinhada ao modelo investigativo, contribui para que uma nova ótica seja aplicada à compreensão crítica dos fenômenos nesse campo teórico. Temas como governo, governamentalidade, ética, construção do sujeito, cuidado de si, moral, formas de subjetivação e objetivação representam uma vasta gama de conteúdos que envolvem diretamente a questóes da cultura e dos significados produzidos socialmente e podem ser investigados, uma vez que eles vêm assumindo uma crescente importância para as organizações, tanto internamente como em seu posicionamento relacional com o mercado.

Como forma de ilustrar algumas possibilidades empíricas, destaca-se a elaboração de pesquisas na área de marketing sobre o posicionamento de marcas e sua relação com formações discursivas e a questão dos relacionamentos entre organizações e consumidores envoltos às questões de relação de poder. $\mathrm{Na}$ área de gestão de pessoas, alguns conceitos foucaultianos já são utilizados, como no campo do comportamento organizacional, no qual temas relacionados com hierarquia e as relações de trabalho também podem ser analisados por meio da lógica das relações de poder. Esses temas podem ser expandidos também em áreas mais tradicionais, como logística, na qual os relacionamentos entre organizações e fornecedores resultam em conflitos e disputas. 
Enfim, a utilização do conceito de solo epistemológico pode ainda contribuir para se desvelarem as racionalidades presentes nas representações sociais, que produzem formas de conhecimentos e de ordenação de realidades, uma vez que este conceito permite problematizar os efeitos do que se considera verdade em determinado tempo e espaço. Um estudo com essa base revela-se próprio para produção de conhecimento crítico em qualquer das áreas de administração.

\section{RefERÊNCIAS}

BATISTA-DOS-SANTOS, Ana Cristina et al.

Epistemologia e Metodologia para as Pesquisas Críticas em Administração: leituras aproximadas de Horkheimer e Adorno. Revista de Administração de Empresas, São Paulo, v. 50, n. 3, p. 312-324. jul./set., 2010.

CASTRO, Edgardo. Vocabulário de Foucault: um percurso pelos seus temas, conceitos e autores. Belo Horizonte: Autêntica, 2009. (447 p.)

COSTA, Flávia Zimmerle da Nóbrega; LEÃO, André Luiz Maranhão de Souza. Desvelamento do limiar discursivo de uma marca global em uma cultura local. Cadernos EBAPE.BR, Rio de Janeiro, v. 9, n. 2, p. 300-332, jun, 2011.

DAVEL, Eduardo; ALCADIPANI, Rafael. Estudos críticos em administração: a produção cientifica brasileira nos anos 1990. RAE - Revista de Administração de Empresas, São Paulo, v.43, n.4, p.72-85, 2003.

FAIRCLOUGH, Norman. Discurso e Mudança Social. Brasília: Editora Universidade de Brasília, 2001. (316 p.)

FOUCAULT, Michel. Arqueologia do saber. 7. ed. Rio de Janeiro: Forense Universitária, 2007. (236p.)

As Palavras e as Coisas. 8. ed. São Paulo:

Martins Fontes, 2000. (421 p.)

Nietzche, Freud, Marx: Theatrum

Philosoficum. São Paulo: Princípio Editora, 1997. (81 p.)

Microfísica do poder. 27. ed. Rio de Janeiro:

Edições Graal, 1979.; (295p.)
. Doença Mental e Psicologia. Rio de Janeiro: tempo Brasileiro, 1975. (71 p.)

. L' Ordre du Discours : leçon Inaugurale du

Collège de France, 2 décembre 1970. Paris: Gallimard, 1971.

GRECO, John. Introdução: o que é epistemologia. In. GRECO, John; SOSA, Ernest. (Org.) Compêndio de Epistemologia. São Paulo: Edições Loyola, 2008. (752 p.)

GUAZZELLI, Iara. O conceito de solo epistemológico. In: Cadernos de Filosofia, São Paulo, v.1, n.1, São Paulo: Instituto Sedes Sapientiae, 1994, p. 1-5

LEÃO, André Luiz Maranhão de Souza; Sérgio Carvalho Benício de. Apresentando a Etnografia da Comunicação ao Campo da Pesquisa em Administração. In: I ENCONTRO DE ENSINO E PESQUISA EM ADMINISTRAÇÃO E CONTABILIDADE - EnEPQ, 2007. Anais... Recife. Recife: ANPAD, 2007, p. 1-10.

LEMKE, Thomas. Foucault, Governmentality, and Critique. In: Rethinking Marxism Conference, University of Amherst (MA), sept., 2000, p. 21-24.

LUNA, W. M. Foucault and ethical subjectivity. In: KRITIKE, Manila, v. 3, n. 2, p. 139-146, 2009.

MACHADO, Roberto. Introdução: por uma genealogia do poder. In: FOUCAULT, Michel. Microfísica do poder. 27. ed. Rio de Janeiro: Edições Graal, 1979. (295p.)

MACHADO, Sérgio Bacchi. A Ideologia de Marx e o discurso de Foucault: convergências e distanciamentos. Sociologias, Porto Alegre, ano 12, n. 23, p. 46-73 jan./ abr., 2010.

MASCARENHAS, André Ofenhejm. Etnografia e cultura organizacional: uma contribuição da antropologia à administração de empresas. RAE - Revista de Administração de Empresas, São Paulo, v. 42, n. 2, p. 88-94, abr.jun., 2002.

O'FARREL, C. Key Concepts. In: Michel-Foucault.com, 2010. Disponível em: <http://www.michel-foucault.com/ concepts/index.html>. Acesso em: 24 jun. 2012. 
SANTOS, Boaventura de Souza. A crítica da razão

indolente: contra o desperdício da experiência. São

Paulo: Cortez, 2000. (415 p.)

SILVEIRA, Rafael Alcadipani da Silveira. Michel

Foucault: poder e análise das organizações. Rio de Janeiro: Editora FGV, 2005, 167 p.

SOUZA, Eloisio Moulin de; JUNQUILHO, Gelson Silva; MACHADO, Leila Domingues; BIANCO, Mônica de

Fátima. A analítica de Foucault e suas implicações nos estudos organizacionais sobre poder. Organizações e Sociedade, Salvador, v. 13, n. 36, p. 13-25, jan/mar., 2006.

THIRY-CHERQUES, H. R. Métodos estruturalistas: pesquisas em ciências de gestão. São Paulo : Atlas, 2008.

VEIGA-NETO, Alfredo. Teoria e Métodos em Michel Foucault (im)possibilidades. In: Cadernos de Educação, FaE/PPGE/UFPel, Pelotas, set.-dez. , p. 83-94, 2009.

Foucault $e$ as Artes de Viver. Dossiê: Foucault $e$ as Estéticas da Existência. Organizada por Margareth Rago.

Revista Aulas, Campinas, UNICAMP. n. 7, 2010. 